\title{
PANDANGAN SOSIOLINGUISTIK DALAM KONTROVERSI TIGA SURAT SULTAN PONTIANAK: STRATEGI KOMUNIKASI DAN KESANTUNAN
}

\section{Agus Syahrani}

\begin{abstract}
Abstrak
Makalah ini membincangkan kandungan yang terdapat dalam tiga surat Sultan Pontianak yang dikirimkan kepada T.S. Raffles. Tiga surat yang dikirimkan oleh Sultan Syarif Kasim Alqadrie kepada T.S. Raffles di Malaka bertanggal 14 Februari, 12 Maret, dan 22 Maret 1811. Perbincangan kandungan fokus kepada tiga warkah Sultan Pontianak yang memunculkan kontroversi aktivitas perompak di masyarakat Melayu Kalimantan Barat. Warkah ini mengandung perkara yang "kontroversial" yaitu mengenai aktivitas perompak yang dilakukan oleh Pengiran Anom dari Kesultanan Sambas. Tiga warkah Sultan Pontianak akan diuraikan berdasarkan struktur surat yang berbeda dari surat Melayu pada umumnya.

Struktur surat menghasilkan bentuk kandungan yang dilihat dari penyampaian pesan yang terpenting dalam surat. Kandungan tiga warkah diuraikan berdasarkan kaidah komunikasi yang digunakan oleh Sultan untuk menyampaikan pesan tentang perkara yang kontroversial dan memunculkan perdebatan sampai sekarang di Kalimantan Barat.

Teknik genre yang digunakan berkaitan dengan strategi komunikasi dan kesopanan yang ditetapkan oleh budaya masyarakat Melayu pada waktu itu. Surat-surat Melayu mempunyai teknik tersendiri berdasarkan strategi komunikasi dan lakuan bahasa yang melibatkan pemeran dalam peristiwa komunikasi. Teknik genre dalam surat Sultan Pontianak juga memiliki teknik tersendiri berdasarkan strategi komunikasi dan lakuan bahasa yang
\end{abstract}


ditetapkan oleh budaya masyarakat Melayu. Lakuan bahasa memperlihatkan aspek kesopanan dalam warkah Sultan Pontianak. Teknik genre yang digunakan dalam warkah Sultan Pontianak berupa kaidah langsung ataupun kaidah tidak langsung memerikan sebuah model kearifan masyarakat Pontianak pada masa lalu yang sampai saat ini model tersebut masih tetap dipelihara sebagai kearifan lokal masyarakat Melayu Pontianak, Kalimantan Barat.

Kata Kunci: Surat Sultan Pontianak, Sosiolinguistik, Kontroversi Kandungan Surat, Strategi Komunikasi, Kesantunan

\section{LATAR BELAKANG}

Keunikan Kesultanan Pontianak terletak pada geografi yang menguntungkan, disebabkan oleh kedudukannya yang dekat dengan Laut Jawa, Selat Karimata, dan Laut Natuna sebagai jalur perdagangan yang menghubungkan Kesultanan Pontianak dengan kesultanan Melayu di kawasan Kalimantan bagian Barat dan Nusantara seperti Riau, Siak, Tambelan, Siantan, Palembang, Banjar, Paser (Rahman, 2000: 4; Alqadrie, 1979;12-16), Terengganu, Banten, Demak, Batavia, kesultanan di utara Jawa, Riau, Deli, Malaka, dan Johor (Iskandar, 1987:58-59,60-62). Letaknya juga tidak terlalu jauh dari kawasan pedalaman yang menghubungkannya dengan kesultanan lain di pedalaman dekat (interior valley) dan pedalaman jauh (interior upland). Oleh karena itu, letak Kesultanan Pontianak juga strategis secara intern di kawasan Kalimantan Barat, terletak pada simpang tiga antara Sungai Kapuas dengan Sungai Landak.

Kedudukannya yang strategis ini memungkinkan Kesultanan Pontianak mampu bertindak sebagai kekuatan pengawas (controlling power) dalam hal pengumpulan/pemasukan pajak dan pungutan lainnya, dan keamanan pengangkutan dengan tujuan perdagangan mauupun kegiatan militer. Oleh karena itu, Kesultanan Pontianak memiliki hubungan yang akrab, menguntungkan, dan menghormati kesultanan lainnya di Nusantara. Tiga pendekatan yang dilakukan oleh Kesultanan Pontianak terhadap para kesultanan atau penembahan di kawasan 
ini menurut Alqadrie (1979:12-16), yaitu: penguasaan, perkawinan, pendalaman agama oleh Sultan dan keluarga kesultanan.

Kedudukan Kesultanan Pontianak yang strategis ini menyebabkan penjajah menggunakan tiga taktik, yaitu (1) taktik penguasaan konvensional tradisional melalui perundingan yang mengawal aktivitas sultan, (2) taktik adu domba atau pecah belah (devide et impera), dan (3) taktik penguasaan "modern" melalui pengembangan kawasan di bagian lain dari kawasan kesultanan sebagai kekuatan pesaing (competing power) untuk melemahkan pusat pemerintahan kesultanan. Dengan taktik tersebut, kesultanan ini berangsur-angsur surut dan hampir kehilangan pengaruh dan kekuasaan terhadap kesultanan lainnya di Kalimantan (Alqadrie, 1979:12-20).

Di alam Melayu, surat telah menjadi alat perhubungan terpenting antara pemerintah lokal dengan orang Barat seperti Inggris, Belanda, dan Portugis. Di samping itu, surat juga digunakan sebagai alat perhubungan antara pembesar lokal dan juga untuk berbagai tujuan sama: untuk tujuan pribadi, hal-hal perdagangan, ekonomi, politik seperti peperangan, penyerahan wilayah, dan sebagainya.

Hubungan yang dibina oleh Kesultanan Pontianak kepada Pemerintah Barat maupun kepada Sultan-Sultan di Kepulauan Melayu sangat tampak dari surat-surat yang dikirimkan oleh Sultan Pontianak. Surat sosial dan surat perjanjian yang dikirimkan oleh Sultan Pontianak kepada Gubernur Jenderal pemerintah Barat seperti Inggris dan Belanda, seperti berikut.

a) Surat Sultan Syarif Kasim Alqadrie kepada T.S. Raffles (12 Maret 1811).

b) Surat Sultan Syarif Kasim Alqadrie kepada T.S. Raffles (14 Februari 1811).

c) Surat Sultan Syarif Kasim Alqadrie kepada T.S. Raffles (22 Maret 1811).

d) Surat Sultan Syarif Kasim Alqadrie kepada T.S. Raffles (1811).

e) Surat Sultan Syarif Usman Alqadrie kepada GJ A.G.P. Baron van der Capellen (27 Mei 1823).

f) Surat Sultan Syarif Usman Alqadrie kepada GJ A.G.P. Baron van der Capellen (18 Desember 1825). 
g) Surat Pangeran Syarif Abu Bakar Alqadrie (Bendahara masa Sultan Syarif Usman Alqadrie) kepada Johan Frederik Walrave van Nes (22 April 1847).

h) Surat Pangeran Syarif Abu Bakar Alqadrie (Bendahara masa Sultan Syarif Usman Alqadrie) kepada J.F. Walrave van Nes (16 Mei 1847).

i) Surat Sultan Syarif Usman Alqadrie kepada Residen Arnoldus Lourens Weddik (18 Maret 1848).

j) Surat Sultan Syarif Yusuf Alqadrie kepada GJ Otto van Rees (11 November 1886).

k) Surat perjanjian meminjam tanah antara Sultan Syarif Abdurrahman Ibn Habib Hussein Alqadrie dengan Willem Adriaan Palm (5 Juli 1779).

1) Surat perjanjian kontrak antara Sultan Syarif Usman Alqadrie dengan Major Nahisy dari Pemerintah Belanda (1819).

Surat-surat dari Gubenur Jenderal pemerintah Barat kepada Sultan Pontianak adalah seperti berikut.

a) Surat dari Kommissaris Jenderal Burggraaf Du Bus de Gisignies kepada Sultan Syarif Usman Alqadrie (11 Februari 1829).

b) Surat dari John Hendric Tobias kepada Sultan Syarif Usman Alqadrie (5 April 1832).

c) Surat dari Sekretari-Jeneral Kommissaris Nederland-Hindi kepada Pangeran Syarif Abu Bakar Alqadrie (Bendaharapada masa Sultan Syarif Usman Alqadrie) bertanggal 4 Agustus 1844.

d) Surat dari Gubenur Jenderal Jan Jacob Rochussen kepada Sultan Syarif Usman Alqadrie (14 Mei 1848).

e) Surat dari Gubenur Jenderal Otto Van Rees di Betawi kepada Sultan Syarif Yusuf Alqadrie (9 April 1877).

Surat-surat dari Sultan Melayu kepada Sultan Pontianak adalah seperti berikut. 
a) Surat dari Pangeran Syed Mursyid Kesuma Negara kepada Sultan Syarif Yusuf Alqadrie (2 Oktober 1872).

b) Surat dari Penembahan Paku Negara Suria Kesuma di Negeri Tayan kepada Sultan Syarif Yusuf Alqadrie (3 Februari 1883).

\section{KAJIAN KEPUSTAKAAN}

Kajian ini fokus kepada surat yang dikirim oleh Sultan Pontianak kepada T.S. Raffles. Koleksi surat-surat Sultan Pontianak setelah diperiksa dalam berbagai katalog terdapat di Arsip Nasional Republik Indonesia, Perpustakaan Negara Malaysia, Arkib Negara Malaysia, Perpustakaan Universiti Leiden, dan British Library, kajian Annabel Teh Gallop (1994) terhadap seratus surat bergambar dan manuskrip Melayu yang dihasilkan oleh The British Library untuk Arkib Negara Malaysia, kajian Ab. Razak Ab Karim (1998) dalam disertasi Ph.D beliau terhadap 88 lembarsurat Melayu dari abad ke 16 hingga abad ke-19, dan kajian Mu'jizah (2009) terhadap 50 surat Melayu pada abad ke-18 dan ke-19. Sejauh yang telah diperiksa jumlah surat Sultan Pontianak, adalah 13 lembar, yaitu 11 lembar surat sosial dan 2 lembar surat perjanjian.

Surat sosial yang menjadi tumpuan bahan kajian adalah seperti berikut.

a) Surat Sultan Syarif Kasim Alqadrie kepada T.S. Raffles (14 Februari 1811), British Library (Gallop, 1994).

b) Surat Sultan Syarif Kasim Alqadrie kepada T.S. Raffles (12 Maret 1811), British Library (Gallop, 1994).

c) Surat Sultan Syarif Kasim Alqadrie kepada T.S. Raffles (22 Maret 1811), British Library (Gallop, 1994).

\section{GENRE SEBAGAI TEKS}

Genre sebagai teks telah dikemukakan oleh Halliday dan Hasan (1976:2-4) yang menyatakan genre sebagai rekaman teks sesuatu peristiwa komunikatif. 
Menurutnya, sesuatu struktur bentuk dianggap sebagai teks sekiranya mempunyai hubungan antara satu sama lain dan hubungan antarstruktur ini akan menghasilkan suatu jaringan. Jaringan tersebut akan mewujudkan keutuhan/kepaduan teks sehingga sesuatu struktur memerlukan struktur lain untuk mewujudkan keutuhan. Ditambahkannya, teks mempunyai jaringan yang membedakan dari bentuk yang bukan berupa teks. Jaringan ini dibuat karena wujudnya perkaitan yang utuh dan padu antarstruktur. Suatu unsur akan memerlukan bantuan dari unsur yang lain untuk mewujudkan keutuhan dan kepaduan suatu teks. Teks dapat berupa bahasa pertuturan atau bahasa lisan, bahasa tulisan atau apa-apa saja bentuk sarana yang digunakan untuk menyatakan apa-apa saja yang dipikirkan. Teks mempunyai sifat tertentu dan kata-kata atau ayat-ayat ditulis, teks terdiri dari lambang atau bunyi tulisan yang kemudiannya dikodekan dalam bentuk yang dapat dikomunikasikan. Sebagai satu bentuk yang dapat berdiri sendiri, teks mempunyai makna tertentu atau kesatuan makna. Teks tidak mempunyai batasan seperti struktur tetapi lebih besar daripada itu.

Hubungan serta keutuhan antara struktur dalam sebuah teks menggunakan konsep anafora yang membincangkan jenis-jenis perkaitan yang terdapat di dalam teks dan memberikan kaitan yang mengikat teks tersebut menjadi satu. Perkaitan yang utuh dalam teks secara eksplisit akan mempunyai penanda-penanda formal yang menghubungkan sesuatu yang akan atau telah diperkatakan. Hubungan padu ini dirangkum dalam konsep referensi, penggantian atau penghilangan, dan hubungan-hubungan leksikal.

Referensi adalah bentuk yang tidak ditafsirkan secara semantik tetapi menjurus kepada sesuatu yang lain untuk tafsiran. Bentuk ini memberi petunjuk kepada pembaca untuk mencari tafsiran sendiri. Sekiranya tafsiran yang dibuat terdapat di luar teks, yaitu dalam konteks situasi, hubungan ini dinamakan eksofora. Hubungan ini tidak mempunyai peranan dalam keutuhan suatu teks. Penggantian atau penghilangan menghendaki pembaca mencari hubungan dasar antara bagianbagian teks untuk digantikan ataupun diisi apabila terdapat unsur-unsur ini dalam 
teks. Kedua-duanya saling berkaitan karena hubungan bentuk dan juga referensi yang menimbulkan makna leksikal secara langsung (Halliday dan Hasan,1976:2-4).

Hubungan leksikal akan memperlihatkan keutuhan referensi karena terdapat hubungan leksikal, seperti hiponim, kolokasi, hubungan-hubungan struktural lanjut seperti penggantian klausa, perbandingan, pengulangan sintaksis, kesesuaian kata, pemilihan gaya/stilistik dan sebagainya. Selain hubungan-hubungan tersebut, leksikal juga dipengaruhi oleh tanda-tanda bacaan khusus seperti (;) dan (:) yang akan memperlihatkan hubungan antara ayat-ayat. Ditambahkan bahwa sesuatu teks itu dianggap utuh apabila ia dilengkapi dengan pengertian laras bahasa. Teks merupakan satu-satunya sumber jaringan yang membedakan antara satu teks dengan teks yang lain dan memiliki hubungan-hubungan padu antara ayat-ayat yang menonjol dengan jelas. Pengertian yang lebih sederhana telah didefinisikan kepada teks sebagai bahasa yang berfungsi untuk melaksanakan tugas-tugas tertentu dalam konteks situasi dan sangat berbeda dengan kata-kata atau ayat-ayat yang mungkin ditulis di papan tulis. Teks merupakan semua bentuk bahasa yang hidup dan digunakan dalam konteks situasi, yang boleh berupa bahasa pertuturan (lisan), tulisan atau bentuk-bentuk sarana yang digunakan untuk menyatakan apa saja yang dipikirkan.

Bronislaw Malinowski (dalam Halliday, 1985:7) mencoba menerjemahkan teks-teks dalam bahasa Kiriwinia ke dalam bahasa Inggris tetapi tidak dapat dipahami, walaupun dengan berbagai cara digunakan dan akhirnya dapat disadari diperlukan suatu istilah yang dapat mengungkapkan keseluruhan dengan istilah konteks situasi yang bermaksud lingkungan tempat teks tersebut diucapkan. Teori Malinowski memerikan perkara yang lebih luas, seperti berikut.

1) Bahasa menggambarkan perlakuan, menjelaskan masyarakat dan fungsi-fungsi emotif kesadaran tentang penggerak bahasa (communication phatic).

2) Bahasa tidak boleh dilihat dalam bentuk yang terasing dari konteks sosial dan kepentingan makna bagi sesuatu ujaran itu didapati dalam penggunaan dan kedudukannya. 
3) Seseorang itu perlu memiliki sejarah budaya para pemeran untuk memahami makna yang diperkatakan secara keseluruhan serta jenis kegiatan yang berkaitan, baik yang bersifat praktis maupun bersifat ritual. Oleh karena itu, konteks situasi dan konteks budaya diperlukan untuk pengkaji memahami teks dengan sebaik-baiknya.

Dell Hymes (dalam Halliday, 1985:12-17), menyatakan bahwa semua bahasa terikat dengan konteks budaya dan konteks situasi, yang akan menentukan jenis teks. Bahasa yang digunakan dalam berbagai situasi pula menjadikan sesuatu komunikasi itu bermakna. Oleh karenanya, setiap penutur bahasa akan mempelajari ciri-ciri khusus dalam setiap konteks dan menggunakannya dalam setiap situasi. Teks yang memiliki tujuan dan fitur-fitur yang sama dinamakan genre. Teori genre berdasarkan fakta bahwa bentuk pertuturan dan tulisan adalah berbeda, karena fokus utama pada teks bukannya pada ayat-ayat secara terpisah. Teks yang mempunyai ciri konteks dan tujuan yang sama akan berkongsi fitur yang sama. Genre merupakan medan kajian secara teoretikal yang cenderung beranggapan bahwa konvensi-konvensi khusus membentuk kandungan (tema atau latar) dan bentuk (struktur dan gaya) yang menggabungkan ciri-ciri ini dengan teks serta berhubungan antara satu sama lain.

\section{GENRE SEBAGAI SUATU PERISTIWA KOMUNIKASI}

Genre sebagai suatu peristiwa komunikasi yang banyak diutarakan oleh pengkaji, di antaranya adalah Christine (1989) dan Swales (1981, 1990). Christine (1989:74) menyatakan bahwa genre sebagai suatu peristiwa komunikatif merujuk kepada proses-proses sosial karena anggota masyarakat yang mempunyai budaya tertentu akan berinteraksi antara satu sama lain untuk menjadi "goal-oriented" disebabkan mereka merancang sesuatu perkara itu supaya berlaku. Dalam usaha ini anggota masyarakat akan menggunakan lebih dari satu usaha untuk membuat pemeran mencapai tujuan mereka. 
Swales (1981:85-90) mengutarakan pandangan bahwa genre mempunyai tujuan-tujuan komunikatif yang sering berlaku dan dipahami oleh ahli-ahli profesional atau golongan akademik. Menurutnya, peristiwa komunikatif akan dijelaskan dalam bentuk bahasa, kekerapan dan lingkungan kontekstual sesuatu teks itu. Peristiwa komunikatif yang jarang-jarang berlaku juga akan diberikan status genre sekiranya menonjol dalam sesuatu budaya yang ada.

Peristiwa bahasa tidak hanya melibatkan wacana dan juga pemeran tetapi juga ciri-ciri kontekstual, seperti peranan wacana dan juga ciri-ciri fisikalnya, aspek sejarah, dan lingkungan budaya sesuatu masyarakat itu dan ahli-ahli profesional atau golongan akademik. Genre sering digunakan dalam kajian wacana bahasa lisan dan juga tulisan untuk tujuan pengajaran. Genre merupakan suatu kelas peristiwa komunikatif dan kriteria utama yang mengubah sesuatu peristiwa komunikasi menjadi genre adalah penggabungan tujuan-tujuan komunikasi yang sama.

\section{STRATEGI KOMUNIKASI DALAM SURAT SULTAN PONTIANAK}

Strategi komunikasi merupakan cara-cara ataupun kaidah-kaidah yang digunakan oleh pemeran-pemeran yang terlibat dalam sesuatu peristiwa bahasa. Pemeran adalah orang-orang yang terlibat dalam sesuatu perbincangan ataupun peristiwa bahasa. Kata pemeran disesuaikan dengan istilah bahasa Inggris participants. Menurut Asmah Hj. Omar (1995:50-51), strategi komunikasi yang digunakan oleh anggota masyarakat adalah bertujuan untuk mendapatkan sesuatu informasi, penjelasan yang lebih lanjut, memastikan komunikasi berjalan lancar dan berlanjut, dan seterusnya.

Berkaitan dengan strategi komunikasi sebagai peristiwa bahasa, Hymes (1968:99) telah mengemukakan faktor penanda terjadinya peristiwa bahasa, yaitu, latar dan tempat (setting and scene), pemeran (participants), tujuan dan matlamat (end), bentuk ujaran (act sequences), nada(key), alat (instrumentalities), norma interaksi dan interpretasi (norms of interactions and interpretation), dan bentuk penyampaian 
(genres). Pendapat ini yang lebih dikenal dengan akronim SPEAKING yang menunjukkan sesuatu yang kompleks berlakunya suatu peristiwa bahasa yang berhubungan dengan konsep komunikasi sebagai proses akhir dalam sebuah peristiwa bahasa. Peristiwa bahasa itu sendiri adalah peristiwa terjadinya atau berlangsungnya interaksi linguistik dalam suatu bentuk ujaran yang melibatkan dua pihak, yaitu penutur dan lawan berbicara. Peristiwa bahasa turut mementingkan persoalan pokok yang dibicarakan, pada waktu tertentu, tempat, serta situasi tertentu.

Dalam masyarakat Melayu tradisional berdasarkan surat-surat Melayu, Ab. Razak Ab. Karim, (2000:2) mengatakan bahwa terdapat dua jenis teknik komunikasi yang digunakan, yaitu teknik langsung dan teknik tak langsung. Teknik langsung adalah teknik yang digunakan oleh seseorang untuk meminta atau memberikan sesuatu informasi secara terus terang tanpa penggunaan simbol, sedangkan teknik tak langsung adalah kebalikan teknik langsung. Penutur tidak menyatakan sesuatu secara terus terang tetapi menggunakan bentuk ungkapan seperti peribahasa, bidalan, dan sebagainya untuk menyatakan sesuatu itu.

Asmah Hj. Omar (1992: 175-186) juga menyatakan bahwa dalam teknik tak langsung pemeran tidak menyatakan sesuatu dengan terus terang tetapi berlindung di balik kata-kata yang digunakan, ungkapan, ataupun lakuan bahasa tertentu. Lakuan bahasa adalah kata-kata ataupun ucapan-ucapan yang digunakan hanya untuk membuka jalan bagi komunikasi ataupun percakapan seterusnya. Dalam ilmu linguistik London ucapan seperti ini dinamakan phatic communion yang bermakna pembuka komunikasi.

Dalam surat Melayu (Ab. Razak Ab. Karim, 2000:2-4), strategi komunikasi terpapar dalam bagian komponen kata puji-pujian, isi atau kandungan surat dan juga prapenutup surat. Kata puji-pujian adalah kata-kata yang digunakan pada baris awal ataupun permulaan surat untuk menyatakan nama, gelaran, dan juga alamat pengirim surat. Kata-kata yang digunakan ringkas tetapi terkandung banyak pengertian dan juga tujuan yang hendak disampaikan oleh pengirim surat. 
Kandungan surat adalah bagian terpenting dan di sinilah segala permintaan dan juga pesan utama yang hendak disampaikan oleh pengirim surat. Secara umum, kandungan surat-surat Melayu lama terdiri dari aspek-aspek perekonomian, pribadi, perdagangan, politik, serta pengiktirafan seseorang sebagai ketua kerajaan. Bagian prapenutup atau salam adalah bagian awal sebelum sesuatu penutup surat. Ia terdiri dari salam yang merupakan hadiah yang disampaikan kepada penerima berupa binatang, barang-barang, atau sebagainya. Hadiah juga dapat berupa salam, doa, dan kata-kata indah serta beradat yang ditujukan kepada penerima.

Strategi komunikasi dalam surat-surat Sultan Pontianak, juga dilihat berdasarkan pendekatan yang telah diuraikan oleh Ab. Razak dan Ab. Karim dalam surat Melayu. Strategi komunikasi yang digunakan adalah kaidah langsung dan kaidah tak langsung yang dipaparkan dalam tiga komponen surat Sultan Pontianak, yaitu kata-kata pujian, kandungan, dan prapenutup. Kedua kaidah yang digunakan dalam strategi komunikasi surat Sultan Pontianak dipaparkan berdasarkan pendekatan yang dikemukakan oleh Asmah Hj. Omar (1984 dan 1992) tentang bentuk komunikasi masyarakat Melayu zaman dahulu. Paparan komponen kaidah strategi komunikasi dalam surat Sultan Pontianak memberikan perbedaan dari surat Melayu pada umumnya.

\section{KAIDAH DOA}

Dalam kaidah doa, pihak pengiklan seolah-olah mendoakan bahwa bakal pengguna barangnya akan mendapat kebaikan. Kaidah ini menggunakan perkataan agar yang mengambil alih tempat semoga, moga-moga, atau mudah-mudahan yang lebih panjang bentuknya (Asmah Hj. Omar, ibid:31).

Dalam surat-surat Melayu, kaidah doa digunakan oleh pengirim untuk mendoakan seseorang penerima. Pengirim akan mendoakan penerima tanpa mengira agama yang dianuti oleh seseorang itu. Kebanyakan doa yang digunakan oleh pengirim ditujukan khusus kepada pegawai-pegawai Inggris dan Belanda yang 
mempunyai tingkatan sosial yang tinggi menurut pengirim. Seseorang pengirim akan menggunakan frasa-frasa tertentu untuk ditujukan kepada penerima (Ab. Razak Ab. Karim, 2000: 205-206).

Sultan Pontianak juga menggunakan kaidahdoa ini dalam surat-surat beliaukepada pihak Belanda maupun pihak Inggris, antara frasa yang terkandung dalam doa adalah:

1) sihat dan afiat,

2) selamat,

3) beroleh umur panjang,

4) selamat sentosa,

5) melakukan berkasih-kasihan,

6) melakukan perangai yang amat lemah lembut,

7) bertambah-tambah pangkat derajat,

8) martabat yang kepujian di dalam dunia,

9) sihat wa al-'afiyah,

10) sejahtera selama-lama,

11) selamat sejahtera selama-lamanya,

12) sihat dan selamat sejahtera yang berkekalan selama-lamanya,

13) dengan untung yang baik jua adanya, dan

14) boleh selamat beroleh umur panjang.

Sebelum frasa yang terkandung dalam doa ini terdapat penggunaan kata pohonkan, boleh, minta', mudah-mudahan, dan dipercintakan, untuk mendukung maksud harapan ataupun tujuan. Kebanyakan surat Sultan Pontianak menggunakan kata pohonkan yang bermaksud mohonkan atau mudah-mudahan sebelum sesuatu doa itu dikemukakan. Oleh itu, kata pohonkan merupakan penanda (marker) doa yang dikemukakan karena Sultan mempunyai harapan tertentu terhadap doa yang ditujukan itu. Pada bagian akhir doa, pengirim menggunakan kata jua adanya 
sebagai pengganti kata amin (perkenankanlah) sebagai harapan agar doa yang diminta itu diperkenankan oleh Tuhan, seperti terlihat seperti berikut:

1. ... maka dipohonkan atasnya ...,

2. ...jika boleh kita minta'...,

3. ... boleh selamat ...,

4. ... semua minta' ...,

5. ... umur panjang jua adanya ...,

6. ... selama-lamanya jua adanya ...,

7. ... maka mudah-mudahan barang ..., dan

8. ... hanyalah dipercintakan di dalam sihat ... .

Dalam surat yang diutuskan oleh Sultan Syarif Kasim Alqadrie kepada T.S. Raffles pada 14 Februari 1811, baginda telah menggabungkan frasa-frasa 1), 2), 3) dan 13) di atas sebagai doa baginda kepada T.S. Raffles. Doa yang digunakan adalah seperti berikut:

...maka dipohonkan atasnya beroleh sihat dan afiat beserta beroleh selamat umur panjang dengan untung yang baik jua adanya ...

\section{KAIDAH PERISYTIHARAN}

Menurut Asmah Hj. Omar (1992: 20-21), kaidah perisytiharan dalam iklanan bermakna memberitahukan kepada umum tentang adanya sesuatu yang baru atau istimewa. Kata isytihar yang biasa digunakan adalah memperkenalkan atau mempersembahkan yang lebih memberi kesan gema yang bisa juga didukung oleh perkataan-perkataan seperti membawakan walaupun kurang hebat dalam memberikan kesan makna.

Dalam kajian Ab. Razak Ab. Karim tentang surat-surat Melayu, bentukbentuk kaidah perisytiharan ini tidak muncul dalam selembar surat yang dikirimkan oleh Sultan kepada pihak-pihak Barat. Dikatakan bahwa dalam surat Melayu sebagai 
bahan kajian hanyalah menggunakan empat kaidah saja, yakni kaidah pernyataan, kaidah perbandingan, kaidah doa, dan kaidah penceritaan semula.

Kaidah perisytiharan digunakan dalam Surat Sultan Syarif Kasim Alqadrie kepada T.S. Raffles, pada 12 Maret 1811 seperti dalam petikan berikut.

... dipermaklumkan oleh Sultan Syarif Kasim Alqadrie kepada sahabat kita Tuan Raffles maka adalah kita memberi khabar kepada sahabat kita akan hal Pangeran Anom Sambas beserta Abdul Rasyid Mento' itu datang ke Kuala Pontianak merampok2 bersama2 ilanun mengambil sebuah wangkang Cina, ...

Kata isytihar yang digunakan dalam surat ini adalah kata maklum yang mendapat bentuk morfem terikat kompleks diper-kan. Asmah Hj. Omar (2009:14) menyatakan bahwa morfem terikat kompleks merupakan gabungan dua morfem terikat atau lebih. Dalam bahasa Melayu, penggabungan dapat berlaku pada awalan saja atau pada awalan dan akhiran. Makna kombinasi afiks diper-kan dengan bentukan verba adalah dijadikan supaya (Harimurti Kridalaksana, 1996:57). Makna kata dipermaklumkan dalam surat ini adalah dijadikan supaya maklum.

Kaidah perisytiharan yang digunakan oleh Sultan dalam surat ini adalah untuk memberitahukan T.S. Raffles bahwa keadaan negeri Pontianak tidak aman disebabkan perompak yang merampok dan dipimpin oleh Pangeran Anom Sambas. Kaidah ini digunakan oleh Sultan untuk memberitahukan dan menyatakan bahwa perompak yang diperkatakan merupakan suatu perkara penting dan istimewa. Hal ini dilakukan oleh Sultan dengan maksud supaya T.S. Raffles segera memberantas perompak tersebut. Kaidah perisytiharan yang termaktub dalam surat ini memperlihatkan sesuatu yang ingin Baginda nyatakan secara jelas. Kaidah perisytiharan yang terlihat dalam kandungan surat mengandung penyataan, pemberitahuan, dan pengumuman yang hendak disampaikan oleh Sultan dalam suratnya.

\section{KAIDAH NASIHAT}


Kaidah iklan yang dikemukakan oleh Asmah Hj. Omar (1992: 37-38), merupakan bentuk yang tidak langsung dalam konteks suruhan. Suruhan yang tidak langsung dipahami sebagai kaidah nasihat. Dalam kaidah nasihat tujuannya agar retorik syarat dapat dicapai. Penanda retorik syarat menggunakan perkataan jika.

Dalam surat Sultan Pontianak, kaidah nasihat digunakan oleh Sultan untuk menyampaikan suatu nasihat terhadap sesuatu hal. Penggunaan kaidah nasihat ditandai dengan kata jika sebagai kata hubung yang menyatakan syarat. Seperti yang dikatakan dalam kaidah iklanan, penggunaan kata ini menunjukkan kaidah nasihat secara tidak langsung. Kata jika digunakan oleh Sultan sebagai strategi komunikasi yang bermakna syarat. Strategi komunikasi yang dimaksudkan bahwa Sultan memahami perbedaan status antara Sultan sebagai pengirim dan penerima surat. Sultan tidak menggunakan kaidah suruhan secara langsung, tetapi menggunakan secara tidak langsung. Sultan memahami status penerima surat yang tinggi sehingga kaidah suruhan secara tidak langsung digunakan sebagai bentuk kaidah nasihat. Penggunaan kaidah ini tergambar dalam surat Sultan Syarif Kasim kepada T.S. Raffles pada 14 Februari 1811, seperti dalam petikan berikut.

... dan kepada kita punya fikiran, jika kompeni Inggris tiada mahu tolong kerja habis itu perampok2 itu, pastilah di belakang ia kerja kembali kerja rosak sama orang putih, karena yang kita tahu ini telah tiga kali sudah Pangeran Anom beserta Sultan Sambas ini kerja jahat sama Inggris; pertama2, bunuh Kapitan Rasdil; keduanya, bunuh mualim kapal commerce itu; ketiganya, ambil harta Kapitan Ross bersama2 Abang Abdul Rasyid itu. ...

Kaidah nasihat juga terdapat dalam surat Sultan Syarif Kasim kepada T.S. Raffles pada 22 Maret 1811, seperti dalam petikan berikut.

... jika tiada sahabat kita segera menyuruh lekas2 kapal perang datang, pasti ada terlalu banyak susah segala orang2 dagang yang masuk keluar berniaga di negeri Pontianak itu adanya. ... 
Kaidah nasihat yang digunakan dalam surat Sultan Pontianak hanya tergambar pada dua lembar surat. Kaidah nasihat ini digunakan oleh Sultan Syarif Kasim kepada Raffles karena surat yang dikirim oleh baginda berkaitan dengan perompakan di wilayah kekuasaan negeri Pontianak. Perompak-perompak yang mengganggu kegiatan perdagangan mengkhawatirkan Sultan Syarif Kasim. Oleh sebab itu, dalam surat yang dikirim kepada Raffles baginda pun memaklumkan kepadanya dalam bentuk kaidah nasihat. Kaidah ini digunakan oleh Sultan agar Raffles mengambil tindakan dengan cepat untuk mengatasi masalah perompak tersebut. Baginda tidak mau hal-hal lain yang tidak diinginkan terjadi.

\section{KAIDAH SURUHAN}

Kaidah suruhan dalam iklanan merupakan kaidah yang paling nyata dan tidak berlindung di balik bentuk-bentuk bahasa yang samar-samar atau halus. Kaidah suruhan dalam surat-surat Melayu memberikan perbedaan dengan bentukbentuk meminta yang dipengaruhi oleh penggunaan kata-kata penegas yang berulang secara jelas. (Asmah Hj. Omar, 1992: 35).

Surat Sultan Pontianak yang dikirim kepada pihak Inggris menunjukkan penggunaan kaidah suruhan. Kaidah ini digunakan karena kekhawatiran Sultan terhadap permasalahan keamanan dan perdagangan yang terganggu oleh perompak di wilayah negeri Pontianak. Kaidah suruhan ini tergambar dalam kandungan surat. Penanda wujudnya kaidah ini adalah kata-kata penegas yang digunakan oleh Sultan.

Dalam surat Sultan Pontianak digunakan kata-kata penegas yang berulangulang seperti boleh dengan bolehnya, menyuruhkan, menyuruhkan lekas2, dan menyuruh dengan segeranya. Penggunaan kata penegas ini memberikan makna sebagai suatu suruhan tanpa berlindung dengan penggunaan bahasa yang samar-samar maupun bahasa halus. Surat Sultan Pontianak yang menggunakan kaidah suruhan ini, hanya terdapat dalam dua surat, yaitusurat Sultan Syarif Kasim kepada T.S. Raffles pada 12 Maret 1811 dan pada 22 Maret 1811, seperti dalam petikan berikut. 
... maka telah sangatlah harap kita dengan amat besar pengharapan kepada sahabat kita Tuan Raffles Esquire akan menyuruhkan sebuah kapal perang datang ke Pontianak dengan segeranya, karenaPangeran Anom beserta Abdul Rasyid itu ada sedia di laut Kuala Pontianak merompak2 dengan dua buah kapal kecil jua adanya....

... maka inilah jika boleh dengan bolehnya kita minta' tolong kepada sahabat kita menolong menyuruhkan sebuah kapal perang ke Pontianak menangkap si pencuri itu, dan kita pun boleh pergi bersama2 kapal perang itu menangkap si pencuri itu. Jika tiada sahabat kita segera menyuruhkan lekas2 kapal perang datang, pasti ada terlalu banyak susah segala orang2 dagang yang masuk keluar berniaga di negeri Pontianak itu adanya. Maka telah sangatlah harap kita dengan amat besar pengharapan kepada sahabat kita Tuan Thomas Raffles Esquire akan me\{n\}yuruhkan sebuah kapal perang datang ke Pontianak dengan segeranya, karenaPangeran Anom beserta Abdul Rasyid itu ada sedia di laut Kuala Pontianak merompak2 dengan dua buah kapal kecil jua adanya.

Kaidah suruhan yang digunakan dalam surat memberikan pengertian bahwa Sultan sebagai pengirim surat meminta sesuatu tindakan yang tegas dari penerima surat berhubung permasalahan yang termaktub dalam kandungan surat yang dikirim kepada pihak Inggris. 


\section{KESOPANAN DALAM SURAT SULTAN PONTIANAK}

Asmah Hj. Omar (1996: 90) menyatakan bahwa dalam bahasa Melayu terdapat dua jenis kesopanan, yaitu kesopanan berkendala dan kesopanan asas. Kesopanan asas adalah kesopanan yang telah ada dan menjadi pedoman bagi anggota masyarakat untuk berhubungan antara satu dengan yang lain. Kesopanan berkendala pula adalah kesopanan yang menggambarkan usaha yang dilakukan oleh anggota masyarakat dalam hubungan dengan memberikan perhatian pada kendala-kendala tertentu.

Dalam masyarakat Melayu tradisional, terutama masyarakat yang digambarkan dalam surat-surat Melayu (Ab. Razak Ab.Karim, 1998: 210-213) mengatakan bahwa kesopanan berbahasa di kalangan masyarakat dapat diukur berdasarkan pendekatan yang digunakan oleh Dell Hymes (1974: 16-22). Menurutnya, ada empat faktor yang menjadi penentu kesopanan penggunaan bahasa di kalangan masyarakat, yaitu berdasarkan siapa yang bercakap dengan siapa tentang apa, di mana, mengapa, dan bagaimana. Keempat-empat faktor ini mempunyai perkaitan dalam menentukan penggunaan kesopanan berkendala yang perkatakan oleh Asmah Hj. Omar.

Faktor mengapa berkaitan dengan tujuan sesuatu ucapan disampaikan sama ada untuk menyampaikan informasi, ulasan, ataupun sebagainya. Dalam surat Sultan Pontianak faktor ini berkaitan dengan faktor apa yang diperkatakan oleh pengirim surat. Kedua-dua faktor ini saling berkaitan antara satu sama lain. Tujuan surat dikirimkan terlihat dalam kandungan surat Sultan Pontianak, misalnya perkara politik. Perkara politik dalam surat Sultan Pontianak memerikan bentuk yang unik karena dalam dua bulan saja tiga lembar surat telah dikirim oleh Sultan Syarif Kasim Alqadrie kepada Raffles untuk mengabarkan bahwa Pontianak berada dalam keadaan tidak aman akibat dari kegiatan perompak yang dilakukan oleh Pangeran Anom dan Abdul Rasyid Mentok dari Sambas. Isi kandungan yang sama memerikan pentingnya perkara yang termaktub dalam tiga lembarsurat yang dikirim. Hal yang 
demikian menjadi unik dan tidak terdapat dalam surat-surat Melayu pada umumnya. Sultan masih mengedepankan kesopanan berbahasa dalam suratnya, dengan digunakannya faktor apa sebagai bentuk kesopanan. Pemilihan kata digunakan oleh baginda kepada Raffles tentang negeri Pontianak yang tidak aman disebabkan oleh perompak.

\section{HUBUNGAN STRATEGI KOMUNIKASI DAN KESOPANAN}

Strategi menurut Asmah Hj. Omar (1996:93) merupakan kaidah yang digunakan oleh pemeran untuk mencapai tujuan tertentu. Jika strategi dikaitkan dengan kesopanan, maka strategi itu sendiri hendaklah ditandai oleh kesopanan, yakni tingkah laku dan tutur kata yang sopan. Tidak semua strategi komunikasi kebahasaan merupakan strategi sopan karena ada yang tidak mementingkan kesopanan, tetapi mementingkan pencapaian tujuan dengan cara apapun.

Hubungan strategi komunikasi dan kesopanan terdapat dalam surat-surat Melayu lama yang telah dikaji oleh Ab. Razak Ab. Karim (1998:213-215). Dalam kajian surat Melayu lama terdapat hubungan antara strategi komunikasi dengan kesopanan karena dalam strategi komunikasi terdapat ciri-ciri kesopanan, yaitu tingkah laku dan tutur kata yang sopan. Untuk melihat hubungan ini terdapat beberapa faktor dalam strategi komunikasi yang menandakan kesopanan. Faktorfaktor tersebut adalah:
a) hubungan peranan,
b) perbedaan taraf sosial,
c) perwujudan kekuasaan,
d) menjaga air muka (kehormatan),
e) kepatuhan pada tajuk atau bidang, dan
f) kepatuhan pada peraturan surat menyurat. 
Hubungan strategi komunikasi dengan kesopanan juga tergambar dalam surat-surat Sultan Pontianak. Hubungan ini memiliki kesamaan seperti yang terdapat dalam surat Melayu. Kesamaan ini tergambar dengan penggunaan faktorfaktor dalam strategi komunikasi yang menandakan kesopanan. Kesamaan unsur strategi komunikasi surat Melayu menunjukkan bahwa Sultan Pontianak menggunakan kaidah kesopanan sebagai bentuk strategi komunikasi dalam suratsuratnya. Faktor ini diterapkan dalam surat Sultan Pontianak untuk melihat kesesuaian unsur strategi komunikasi dan kesopanan yang digunakan oleh Sultan Pontianak kepada penerima surat. Faktor-faktor tersebut dalam surat baginda adalah menjaga air muka.

Dalam konteks surat-surat Sultan Pontianak, faktor menjaga air muka (kehormatan) sangat dititikberatkan karena ia melibatkan dua pihak atau antara dua buah kerajaan. Sebagai sultan, baginda perlu menjaga kehormatan pihak yang satu agar hubungan antara negeri Pontianak dengan pihak Barat tetap utuh dan hubungan yang terjalin tetap kekal. Gambaran kesopanan bahasa dalam surat Sultan Pontianak dapat dilihat dalam kepala surat, kata-kata pujian, prapenutup, dan penutup surat.

Kesopanan dalam kepala surat dinyatakan dengan penggunaan bahasa kiasan dengan nama-nama Tuhan. Kesopanan juga tergambar dalam bagian puji-pujian dengan penggunaan berbagai bentuk strategi komunikasi. Penggunaan kata-kata pujian surat sosial Sultan Pontianak adalah dengan konsep waktu dan dieksploitasi dengan pengukuhan yang dikaitkan oleh penulis dalam bentuk kiasan sebagai sandaran terhadap pujian yang disampaikan oleh pengirim. Selain itu, baginda juga menggunakan kaidah doa yang merupakan gaya yang digunakan oleh Sultan agar hubungan mereka kekal. Baginda juga menggunakan kaidah pernyataan yang bertujuan untuk memberitahukan sesuatu tentang diri penerima surat dan untuk memaparkan bahwa penerima mempunyai sifat tertentu yang tiada bandingnya dengan orang lain pada waktu itu. 
Unsur menjaga kehormatan juga tergambar dalam bahasa sopan yang digunakan oleh Sultan dalam bagian prapenutup. Dalam bagian ini Sultan merendahkan diri dengan pemberian hadiah yang ditujukan kepada penerima. Sultan meminta pihak penerima supaya tidak merendahkan atau menjatuhkan kehormatannya dengan hadiah yang diberikan. Unsur ini bersifat terus terang dari Sultan. Antara unsur penggunaannya dalam surat Sultan Pontianak dapat dilihat seperti di bawah ini.

... dan lagi sahabat kita minta' surat undang2 beserta surat Hikayat Raja Iskandar itu, adalah kita kirimkan bersama2 surat ini dalam tangan Kapitan Tait, beserta satu tombak beremas akan hadiah kita kepada sahabat kita kan tanda hati kita sangat putih lagi ikhlas; melainkan jangan sahabat ambil kecil2 hati karena kita ada satu orang miskin ...

Surat Sultan Syarif Kasim Alqadrie kepada T.S. Raffles (14 Februari 1811)

\section{KANDUNGAN TIGA SURAT KONTROVERSI SULTAN PONTIANAK}

Kandungan merupakan bagian terpenting dalam surat. Di bagian inilah tercatat segala permintaan atau pesan yang hendak disampaikan oleh pengirim kepada penerima surat. Kandungan surat dan bagian kata puji-pujian dipisahkan oleh kata tertentu dan biasanya kata $w a b a^{\prime}$ dahu dan 'amma $b a$ ' dahu yang bermaksud selepas itu. Selain kata ini, sering kali kata seperti maka dan kemudian daripada itu digunakan untuk memisahkan kedua-dua bagian ini (Ab. Karim, 1998:52-56).

Semua kata ini akan ditulis lebih besar atau lebih tebal sebagai petunjuk yang memisahkan kedua bagian. Sering kali seni hias (iluminasi) tertentu juga digunakan, tetapi bukanlah sesuatu yang lazim. Kadangkala tulisannya sama saja bentuk dan tidak ada perbedaan yang nyata. Kandungan surat dimulai dengan ucapan terima kasih dari pengirim apabila surat tersebut merupakan surat balasan dari pengirim. Pengirim juga akan menyebut hadiah yang dikirim bila surat yang diterima mempunyai hadiah sebagai cinderamata. Walau bagaimanapun, apabila surat biasa, pengirim akan terus menyatakan isi pertama yang ingin disampaikan kepada penerima (Gallop, 1994:70-72). 
Dari aspek lain pula, kebanyakan kandungan surat yang ditulis oleh juru tulis menggunakan bahasa yang sederhana. Dengan kata lain, penulis sangat kurang menggunakan bentuk perumpamaan dan kiasan. Setiap isi akan ditandai oleh kata pangkal kalimat, seperti maka, syahadah dan waba'dahu, sebagai tanda sesuatu kalimat baru dan isi baru dinyatakan. Asmah (1992:9-17) menyatakan bahwa kata maka dan syahdan merupakan sebagian daripada kata yang digunakan untuk menggantikan tanda titik dalam kalimat. Kedua kata ini digunakan oleh tukang cerita tradisional sebagai urutan sesuatu peristiwa. Kata ini berfungsi sebagai penanda wacana temporal (waktu) dan sebagai satu alat kohesi yang melibatkan wacana tersebut.

Kandungan 'kontroversi' Sultan Pontianak yang terdapat dalam surat surat Sultan Syarif Kasim Alqadrie kepada T.S. Raffles pada 14 Februari 1811. Baginda telah mengabarkan kepada Raffles bahwa baginda meminta bantuan karena Pontianak diancam oleh lanun di bawah pimpinan Pangeran Anom dari Sambas. Baginda telah memberi peringatan kepada Raffles sekiranya beliau tidak mengambil tindakan, pihak Inggris akan terkena dampak dari kegiatan mereka itu. Menurut baginda:

... Jika boleh dengan sebolehnya sahabat kita tolong seboleh-bolehnya kerja habis itu perompak2 dan Ilanun segala yang kerja jahat2 sama orang dagang itu, karena kepada ketika ini semuanya ada berkumpul dalam negeri Sambas dan berkumpul di laut kuala negeri Mempawah dan Pontianak demikianlah adanya. Dan kepada kita punya fikiran jika Kompeni Inggris tiada mahu tolong kerja habis itu perompak2 itu pastilah di belakang ia kerja kembali kerja rosak sama orang putih karena yang kita tahu ini telah tiga kali sudah Pangeran Anom beserta Sultan Sambas ini kerja jahat sama Inggris ...

Lebih kurang sebulan kemudian, baginda mengutus lagi surat yang bertanggal 12 Maret 1811 dan dalam surat ini Sultan Syarif Kasim Alqadrie telah menyatakan bahwa Pangeran Anom dari negeri Sambas dan Abdul Rasyid Mentok telah merampas kapal Mister Hare Malaka dan juga merampas sebuah wangkang dari Cina yang datang untuk berniaga di Pontianak dan Mempawah. Mereka telah merusakkan perdagangan dan mengganggu para pedagang yang keluar dan masuk 
berdagang. Baginda telah meminta bantuan Raffles agar sebuah kapal perang dikirim dengan segera ke Pontianak untuk menangkap pencuri-pencuri tersebut karena mereka berada di laut Kuala Pontianak. Menurut baginda:

... Maka inilah jika boleh dengan bolehnya kita minta tolong kepada sahabat kita menolong menyuruhkan sebuah kapal perang ke Puntianak menangkap si pencuri itu, dan kita pun boleh pergi bersama2 kapal perang itu menangkap si pencuri itu. Jika tiada sahabat kita segera menyuruhkan lekas2 kapal perang datang pasti ada terlalu banyak susah segala orang2 dagang yang masuk keluar berniaga di negeri Pontianak itu adanya ...

Dalam surat ketiga yang bertanggal 22 Maret 1811, baginda memberi informasi kepada Raffles bahwaPangeran Anom Sambas serta Abdul Rasyid Mentok telah membunuh Kapitan Ross di Laut. Baginda mengatakan sekali lagi masalah yang dihadapi akibat dari kegiatan perompak di Pontianak. Dalam dua bulan saja tiga lembar surat telah dikirim oleh baginda kepada Raffles untuk memberitahukan bahwa Pontianak berada dalam keadaan tidak aman akibat dari kegiatan perompak dan rampasan yang dilakukan oleh Pangeran Anom dan Abdul Rasyid Mentok.

Penanda kandungan dalam surat Sultan Pontianak lebih dominan menggunakan kata wa ba'dahu sebagai kata pangkal ayat. Selain kata pangkal kalimat, terdapat juga kata yang digunakan untuk memisahkan kedua bagian dalam kandungan surat. Kata pemisah yang digunakan dalam surat Sultan Pontianak adalah syahdan lagi, syahdan maka, syahdan, syahdan dari, dan maka. Kata pemisah ini selalu digunakan setelah kata pangkal kalimat untuk menandakan sebagai permulaan paragraf baru. Kata pemisah ini memberikan makna kewujudan kepatuhan pada peraturan surat-menyurat.

Isi kandungan yang sama memerikan pentingnya perkara yang termaktub dalam tiga lembar surat yang dikirimkan. Hal yang demikian menjadi unik dan tidak terdapat dalam surat-surat Melayu pada umumnya berdasarkan kajian yang telah dibuat oleh para ahli. 


\section{KONTROVERSI PEROMPAK DAN DEKRIT MELAYU 2010}

Tiga surat Sultan Pontianak yang dijadikan bahan kajian merupakan surat yang dikirimkan oleh Sultan Syarif Kasim Alqadrie kepada T.S. Raffles bertanggal 14 Februari 1811, 12 Maret 1811, dan 22 Maret 1811. Masa pengiriman yang sangat singkat pada masa itu menimbulkan pemaknaan yang kontroversial karena kandungan surat yang dikirimkan sangatlah penting untuk mendapatkan tanggapan dari T.S. Raffles.

Hal kontroversi juga termaktub dalam kandungan ketiga surat yang dikirim itu. Kandungan ketiga surat yang dikirim mengikhtisarkan permasalahan kegiatan perompakan atau perompak yang dilakukan oleh Pangeran Anom dari Kesultanan Sambas. Zainuddin Isman dalam Surat Kabar Borneo Tribune bertanggal 20 Juli 2010, menyatakan bahwa aktivitas perompak merampok kapal-kapal dagang Eropa di perairan laut itu terus berlanjut. Ketika Inggris masuk ke Sarawak pada awal abad ke-19, kegiatan perompak merompak kapal-kapal dagang dari Eropa masih sering terjadi di perairan laut pantai Barat dan laut pantai Utara Kalimantan.

Kapal dagang Commerce milik Syarikat Hindia Timur Inggris yang mengalami kerusakan kemudi adalah salah satu kapal yang dirompak dan dibakar oleh perompak di perairan laut Sarawak. Tidak berapa lama kemudian kapal layar Malacca juga telah dirampas oleh Sultan Sambas dalam tahun 1811 sehingga menimbulkan kemarahan Raffles, Gubernur Jenderal Inggris di tanah Jawa. Raffles kemudian mengutus F. Burn ke Pontianak dan melantiknya menjadi perwakilan politik dan perdagangan.

Berkaitan dengan kasus perompak inilah, Walikota Singkawang- Kota terbesar ketiga setelah Pontianak, yang berbatasan dengan wilayah Sambasbernama Hasan Karman dikritik besar-besaran oleh masyarakat Melayu yang ada di Kalimantan Barat. Hasan Karman dikritik karena isi kontroversial dalam makalah yang beliau paparkan dalam Diskusi Buku Figh Melayu pada tanggal 26 Agustus 2008. Di dalam presentasinya yang berjudul "Sekilas Melayu Asal Usul dan 
Sejarahnya", beliau mengemukakan bahwasannya Melayu adalah lanun atau perompak.

Penyataan inilah yang sangat melukai hati puak-puak Melayu dan Kesultanan Sambas. Kenyataan ini menyebabkan diterbitkan "Dekrit Melayu 2010" yang ditandatangani oleh wakil dari Kesultanan Sambas, Kesultanan Mempawah, Kesultanan Pontianak, Kesultanan Sukadana, dan wakil dari puak-puak Melayu lainnya (Pontianak Post, 29 Mei 2010).

Dekrit Melayu 2010 memberikan suatu kenyataan tentang bukti-bukti sejarah yang diungkapkan melalui kenyataan yang ada dalam Surat Sultan Pontianak. Kaidah-kaidah komunikasi yang digunakan oleh Baginda dalam tiga surat yang dikirim kepada T.S. Raffles memberikan kenyataan tentang ikhwal politik dan perdagangan serta pergumulan dalam Kesultanan Melayu pada waktu itu, terutama Kesultanan Melayu di pesisir Barat Kalimantan. Pangeran Anom dari Kesultanan Sambas yang selalu dinyatakan dalam ketiga surat Baginda sebagai perompak karena merompak kapal-kapal Eropa yang membawa emas, intan, dan lada hitam dari Sambas mendapatkan perlindungan dari Kesultanan Sambas.

\section{PENUTUP}

Secara umum kajian ini penting untuk dilakukan karena surat-surat Sultan Pontianak sebagai bahan kajian utama belum ramai dijumpai. Warkah-warkah Sultan Pontianak memberikan suatu pandangan baru dari segi sejarah Kesultanan Pontianak, bila dilihat dari surat sebagai sebuah proses komunikasi. Kesultanan Pontianak sebagai sebuah kesultanan yang paling muda di tamadun Melayu Kalimantan Barat, lahir pada saat kompeni Belanda dan Inggris sudah menjajah wilayah Nusantara sehingga proses komunikasi sultan yang berkuasa menarik untuk dikaji dan memberikan sumbangan pemahaman baru bagi masyarakat Melayu secara menyeluruh. 
Struktur tiga warkah Sultan Pontianak merupakan suatu proses yang diikuti oleh proses yang lain. Tiga warkah Sultan Pontianak memiliki binaan yang selalu dimulakan dengan kepala surat sebagai proses pertama yang diikuti oleh proses berikutnya. Kaidah perisytiharan yang digunakan oleh Sultan dalam warkah adalah untuk memberitahukan T.S. Raffles bahwa keadaan negeri Pontianak tidak aman disebabkan perompak yang dipimpin oleh Pengiran Anom Sambas. Kaidah ini digunakan oleh Sultan untuk memberitahukan dan menyatakan bahwa perompak merupakan suatu perkara penting dan istimewa. Hal ini dilakukan oleh Sultan dengan maksud supaya T.S. Raffles segera memberantas perompak tersebut. Kaidah perisytiharan yang termaktub dalam warkah ini memperlihatkan sesuatu yang ingin Baginda nyatakan secara jelas. Kaidah perisytiharan yang terlihat dalam kandungan warkah mengandung penyataan, pemberitahuan, dan pengumuman yang hendak disampaikan oleh Sultan dalam warkahnya.

Kontroversi aktivitas perompak menjadi pemicu terjadinya peristiwa Dekrit Melayu 2010. Dekrit Melayu 2010 memberikan suatu kenyataan tentang bukti-bukti sejarah yang diungkapkan melalui kenyataan yang ada dalam Surat Sultan Pontianak. Kaidah-kaidah komunikasi yang digunakan oleh Baginda dalam tiga surat yang dikirim kepada T.S. Raffles memberikan kenyataan tentang ikhwal politik dan perdagangan serta pergumulan dalam Kesultanan Melayu pada waktu itu, terutama Kesultanan Melayu di pesisir Barat Kalimantan.

\section{DAFTAR PUSTAKA}

Ab. Karim, Ab. Razak. 1998. Warkah-warkah Melayu Sebagai Suatu Genre. Disertasi Ph.D Fakulti Bahasa dan Linguistik, Universiti Malaya, Kuala Lumpur. 2000. Kesopanan Berbahasa Dalam Warkah Melayu Lama", dlm. Jurnal Dewan Bahasa, Disember 2000.

Kuala Lumpur.

2006 Warkah-warkah Melayu. Dewan Bahasa dan Pustaka:

Ansar Rahman et al. 2000. Perspektif Sejarah Berdirinya Kota Pontianak. Pontianak: Romeo Grafika atas nama Pemkot Pontianak. 
Alqadrie, Syarif Ibrahim. 1979. Kesultanan Pontianak di Kalimatan Barat: Dinasti dan Pengaruhnya di Nusantara. Departemen Pendidikan dan Kebudayaan (Depdikbud), RI. Jakarta - Pontianak: DP3M dan UNTAN.

Ariffin, Raja Masittah Raja. 2001. Bahasa Melayu dalam Warkah Melayu Terpilih. Jurnal Bahasa Jun: 231-263.

Christine, F. 1989 (a). "Genre as Social Processes: Working with Genre", Kertas KerjaLERN Conference, University of Technology, Sydney, hlm. 73-88.

Dodi Iskandar. 1993. Ilmu Pengetahuan Sosial - Sejarah. Jakarta: Penerbit Erlangga.

Dodi Iskandar dan Dedi Persada. 1987. Sejarah Nasional Indonesia dan Dunia. Bandung: Armico.

Gallop, Annabel Teh \& Arp. Benard. 1994. The Legacy of Malay Letters. London: The British Library

Halliday, M.A.K. 1976. Explorations in the Functions of Language, London:Edward Arnold.

Arnold.

1985. An Introduction to Functional Grammar, London: Edward

Hymes, D., 1969. Language in Culture and Society:A Reader in Linguistics and Anthropology, New York: Harper \& Row.

Pensylvania.

1974. Foundation in Sociolinguistics, Pheladelphia: University of

Iskandar, Dodi dan Dedi Persada. 1987. Sejarah Nasional Indonesia dan Dunia. Bandung: Armico.

Kridalaksana, Harimurti. 1993. Kamus Linguistik. Jakarta: Gramedia Pustaka Utama.

Mu'jizah, 2009.Iluminasi dalam Surat-surat Melayu Abad ke-18 dan ke-19, Jakarta:KPG dan Pusat Bahasa.

Neale, Stephen. 1995. Question in Genre. In Approaches to Media: A Reader, ed.Oliver Boyd-Barret \& Chris Newbold, 460-472. London: Arnold.

Omar, Asmah Hj.. 1984. Bahasa Iklan Pernigaan. Kuala Lumpur: Dewan Bahasa dan Pustaka.

Bahasa dan Pustaka.

1992. The Linguistic Scenery of Malaysia. Kuala Lumpur: Dewan

1995. Wacana Temuduga dan Wawancara, Kuala Lumpur:

Dewan Bahasa dan Pustaka.

1996. Wacana Perbincangan, Perbahasan dan Perundingan. Kuala Lumpur: Dewan Bahasa dan Pustaka.

Rahman, Ansar, et al. 2000. Perspektif Sejarah Berdirinya Kota Pontianak. Pontianak: Romeo Grafika atas nama Pemkot Pontianak.

Sallehudin, Noor Suraya binti Adnan. 2008. Perubahan Bahasa dalam Warkah Diraja Melayu: Suatu Kajian Mengenai Surat-Surat Kepada Gabenor dalam Tahun 17861794 dan 1886-1894 Disertasi M.A. Fakulti Bahasa dan Linguistik, Universiti Malaya, Kuala Lumpur. 
Syahrani, Agus. 2013. Warkah-warkah Sultan Pontianak:Analisis Genre. Tesis MMS Jabatan Bahasa Melayu, Akademi Pengajian Melayu, Universiti Malaya, Kuala Lumpur.

Swales, John M. 1981.Aspect of Article Introductions, Birmingham: The University of Aston, Language Studies Unit. 